\title{
Treatment and prevalence of abnormal eruption of permanent canines (Literature review)
}

\author{
Bakaev Zh.N., Olimov S.Sh. \\ Bukhara State Medical Institute named after Abu Ali ibn Sino.
}

\begin{abstract}
The article outlines the foundations of the diagnosis, the prognosis of treatment and the prevalence of abnormal eruption of permanent canines. The author presented a broad review of the literature of both foreign and domestic scientists, detailed the course and prevalence of this pathology. Various methods for assessing X-ray examinations and modern approaches to diagnostics and treatment planning for retention of the upper permanent canines, which are necessary in practice at an orthodontist, are also described.
\end{abstract}

Keywords. Dental anomalies, canine retention, orthopantomography, spiral cone-beam computed tomography.

\section{Introduction}

According to a number of foreign researchers, it has been established that the canines of the upper jaw are the second in frequency of retention, second only to the third molars [31; 34]. According to [33], retention of the canines of the upper jaw occurs in about $2 \%$ of the population, while twice as often in women than in men, and twice as often in the upper jaw than in the lower one. Of all patients with maxillary canine retention $-8 \% 15$ have bilateral retention. Approximately one third of the retained maxillary canines are labial and two thirds are palatal. In the works of authors dealing with the issues of retention, this condition occurs from 4 to $18 \%$ of cases among patients who applied for orthodontic care [5, 13, 32, 34].

An impacted tooth (from Latin - holding, restraining) is a tooth that will not be able to erupt properly, as it is completely or partially covered by bone or thick gum tissue.

In Russia, researchers in 1997 studied 2538 orthopantomograms, among which a violation of eruption (retention) of supernumerary teeth was found in $21.6 \%$ of cases; retarded supercomplete with complete ones - in $55.2 \%$ of cases; complete - in $23.2 \%$ of cases, requests for orthodontic help. Canine retention was diagnosed in $70.77 \%$ [8].

According to data from other domestic scientists in clinical studies, canine retention occurs in $15.4 \%$ of clinical cases [1, $23,27,28]$. In the dissertation work, a Russian scientist who studied an integrated approach to the treatment of anomalies of eruption (retention) of individual teeth, diagnosed 203 impacted teeth in 137 clinical cases, of which $51.1 \%$ was canine retention [30].

A among domestic researchers in their clinical and experimental study, among 6037 patients who applied for orthodontic care, 217 patients with retention were identified, which amounted to $3.59 \%$. At the same time, impacted canines were most often found $-52.9 \%$; central incisors $-38.5 \%$ of cases [22].

Thus, retention of the maxillary canines is one of the most common anomalies in the timing of teething among permanent teeth. In most cases, the presence of an impacted canine in the thickness of the bone tissue does not cause any clinical manifestations. Impacted teeth are very often discovered by chance during x-ray examination of the jaw for any reason. Objective signs of retention are the absence of a corresponding tooth, incorrect position of adjacent teeth in the dentition, the presence of bone protrusion on the outer or inner surface of the body or the alveolar process of the upper jaw, neuralgic pain, a feeling of paresthesia in the teeth or lips, in the absence of diseased teeth and other pathological conditions in the corresponding area of the jaw $[2,8,15,16]$.

The bulk of domestic and foreign researchers indicate that the use of the entire range of modern diagnostic measures with their subsequent thorough analysis contributes to the correct diagnosis and a more predictable course and results of treatment of any anomalies, including anomalies in the timing of eruption (retention) of canines. [3, 10,21,35]. The classical scheme for the examination of orthodontic patients with canine retention is clinical examination, anthropometric methods of facial examination, plaster models of the jaws, graphic methods, functional, X-ray 
examination methods $[11,14,20]$. However, retention of canines with a high degree of probability can be established according to the data obtained from X-ray examination of the alveolar bone segment or jaws [17,24,36,38,39].

A number of authors strongly recommend conducting intraoral close-focus radiographs, panoramic images of the jaws in one or several projections to clarify the localization of the impacted tooth, the condition of its roots and roots of adjacent teeth, as well as to determine the state of the periapical tissues $[11,12,18,34]$. Modern authors recommend using spiral computed tomography, as the most informative today. The authors associate the high reliability of the study with the ability to obtain an image of any anatomical formations in a section from 1 to $10 \mathrm{~mm}$, subsequent modeling of dimensional reconstructions and instant display of the image on the screen without linear or angular distortions. $[4,7,9,12,14]$.

Computed tomography in dentistry has significantly increased diagnostic capabilities, thanks to the accuracy of the image, it becomes possible to get an objective idea of the clinical situation and choose the most accurate and controlled treatment plan. $[4,12,31,37]$.

The diagnostic significance of computed tomography is so great, because during the examination it is possible to obtain images of intravital $1 \mathrm{~mm}$ thick sections of any tissue structures. The basis of the technique consists in the layerby-layer X-ray transmission of the object of study in several directions along the movement of the emitter (X-ray tube). The unabsorbed part of the beams is recorded on the sensors, after which the signal from them is received and processed by the computer system. Further, all data received from the source is displayed as an image of the studied structure on the screen. So, computed tomography allows you to study the modeled structures in any planes without superimposing other images in real time without surgical intervention.

Spiral cone-beam computed tomography is considered as the method of choice for studying patients with dental retention among modern foreign authors [12, 37].

A group of Russian researchers proposed an optimal method for determining the area and size of the elements of the dentition, based on the data of orthopantomography and computed tomography. The technique consists in studying orthopantomograms and computed tomograms in Photoshop through a scale grid with specified parameters [6]. When the image is enlarged, the grid is enlarged taking into account the image, which makes it possible to fairly accurately measure any parameters in the images. This technique allows for a comparative analysis of images obtained from patients at different times and to track the dynamics of changes without linear and angular distortions. This experience has shown that at the present stage of development and integration of medicine and higher mathematics, it has become possible to implement joint achievements in practical dentistry. What makes further research in this direction promising.

Based on the variety of etiological factors leading to the retention of the upper permanent canines, it can be concluded that dynamic observation and regular preventive examinations of the eruption of these teeth in children are necessary, starting from the period of mixed bite [25,26].

Thus, summarizing the literature review of 39 articles, various X-ray research methods can be used to diagnose retention of the upper permanent canines. The most modern of those currently available is spiral cone-beam computed tomography, which combines the acquisition of a large amount of diagnostic data with low radiation exposure to the patient. In the literature, various methods of assessing X-ray studies are described in order to diagnose and plan treatment of retention of the upper permanent canines, however, there are no works concerning the X-ray assessment of the dentition of children during the period of mixed bite in order to prevent the formation of retention of canines. And still, we have no right to judge and insist on the use of this or that technique for X-ray studies, because a lot depends on the economic development of a particular region. It also depends a lot on the doctor - orthodontist, namely in the ability to read the information received by this or that resource.

\section{LIST OF REFERENCES}

1.Azimova Sh.Sh., Abruev U.R., Rasulov M.M. Tish-zhaf tizimi anomalyarining Bukhoro shahar maktab yoshdagi bolalar orasida targalishi. // Dr. Ahborotnomasi. 2020. - No. 1. - S. 23-28 bet.

2.Arsenina, O. I. The use of modern fixed orthodontic fixed equipment in the treatment of patients with various anomalies and deformities of the dentition / O.I. Arsenina, I.V. Gunenkova // New in dentistry. 1994. - No. 3 (special issue) - S. 16-22.

3.Bazhanova, S.N. Reducing the negative impact of retention devices in the passive period of orthodontic treatment: dis. Cand. honey. Sciences: 14.00.21 / Bazhanova Svetlana Nikolaevna. - Stavropol, 2002 .-- 144 p. 
4. Balin, V.N. Experience of using computed tomography in the diagnosis of diseases of the dentoalveolar region / V.N. Balin // Dentistry. - 1994. - No. 1. - S. 30-32.

5. White, A.M. Distal occlusion treatment with functional orthodontic appliances / A.M. White // New in dentistry. - 1997. - No. 1 (special issue). - S. 17-18.

6. Bragin, E. A. Analysis of the area and size of the elements of the dentition according to the data of orthopantomography and computed tomography using the software of a personal computer: method, rec. for students, interns and clinics. residents / E.A. Bragin, E.A. Vakushina, I. V. Romanenko and others - Stavropol, 2005 .-- 18 p.

7 Bragin, E.A. Modern methods of diagnostics, prediction and treatment of disorders of dentition closure: textbook. manual for orthopedist, dentistry for medical students. universities / E.A. Bragin, E.A. Vakushina. Stavropol, 2006 .-- 162 p.

8 Budkova, T.S. Teeth retention, treatment plan and prognosis / T.S. Budkova, I. Yu. Zhigurt, F. Ya. Khoroshilkina // New in dentistry. - 1997. - No. 1 (special issue). - S. 46-53.

9. Vakushina, E.A. Improvement of methods of exposing the crowns of impacted teeth / E.A. Vakushina, E.A. Bragin, V.V. Cheprakov et al. // Orthodontics. - 1999. - No. 3. - S. 2-7.

10.Vakushina, E.A. Complex rehabilitation of adult patients with adentia of the upper lateral incisors. Vakushina, E.A. Bragin, P.A. Grigorenko // Orthodontics. - 2001. - No. 2. - S. 20-22.

11.Vakushina, E.A. Improving the efficiency of diagnostic methods and treatment of patients with impacted teeth. Vakushina, M.O. Desyatnikova // New in the theory and practice of dentistry: collection of articles. scientific. works. - Stavropol, 2003 .-- S. 34-36.

12 Vakushina, E.A. The use of computed tomography in the diagnosis and treatment of impacted teeth / E.A. Vakushina, E.A. Bragin // Orthodontics. - 2004. - No. 2. - S. 43-45.

13.Vakushina, E.A. Method for predicting orthodontic correction of retention of upper permanent canines: US Pat. No. 2269968 / E.A. Vakushina, E.A. Bragin, S.P. Babenyshev and others - M., 20.02.06.

14.Volchek, D.A. Modern methods of examination of patients with retention of canals of the upper jaw / D.A. Volchek // Orthodontics. - 2006. - No. 1.-S. 24-26.

15.Gafforov S.A., Bakaev Zh.N. Features of vza // Stomatologiya. - Tashkent, 2019. - No. 4 (77). - S. 74-79.

16.Gafforov S.A., Bakaev Zh.N. Оғiz by̆shlғi shilliқ қаvati kasalliklari - pathologic aspectlari va prevention of asoslari // Stomatologiya. - Tashkent, 2019. - No. 4 (77). - S. 75-80.

17. Dyachkova, Y. Yu. Diagnosis of anomalies of teeth and dentition using computer technologies / Ya.Yu. Dyachkova // Orthodontics. - 2001.-№2.-p. 29-31.

18. Zhigurt, Yu. I. Plan and prognosis of treatment in the treatment of dental retention: author. dis. .Cand. honey. Sciences: 14.00.21 / Zhigurt. Yuriy Ivanovich - Moscow, 1994 .-- 123 p.

19. Ivanov, L. P. Dynamics of teeth mobility during movement with a dosed load / L.P. Ivanov, E.V. Shcherbakov, V.A. Shcherbakov // MRZh. - 1990. - No. 10, pp. 47 - 53.

20. Ilyina, S. B. Etiology of retention in children / S.B. Ilyina, R.A. Galperin // Materials of the II International, conf. maxillofacial surgeons. -SPb., 1996.-S. 2.

21. Kamysheva, L.I. Clinical and morphological characteristics of retention incisors and canines of the upper jaw / L.I. Kamysheva // New in dentistry. - 1994 - No. 3 (special issue). - S. 38-40.

22. Komarova, T.V. Methods for moving impacted teeth with orthodontic appliances with a dosed load: dis. ... Cand. honey. Sciences .: 14.00.21 / Komarova Tatyana Vladimirovna - Volgograd, 2000 .-- 119 p.

23. Korsak, A.K. Modern technologies in the treatment of retention of permanent teeth in children / A.K. Korsak, T.N. Terekhova // New in dentistry. -1999. - No. 3. - P. 56 -5 8.

24. Nedby, A.A. Retention of incisors. Clinic, diagnostics, treatment: dis. ... Cand. honey. Sciences .: 14.00.21 / Nedbai Anna Alekseevna. - M., 2003 .-- 148 p.

25. Olimov S.Sh. The value of metabolic indices of saliva in the development of dentoalveolar anomalies in children with metabolic syndrome. Bukhoro. 2016. - Bet 33.

26. Olimov S.Sh., Gafforov S.A. Bolalarda tish-zhaғ tizimi nuқsonlari va somatic kasalliklar orasida boғliқlikning ilmiy asoslari. (adabiyotlar sharxi) .// Journal. Stomatologiya. -2019 th No. 1. 60 - 65 bet.

27. Olimov S.Sh., Saidov A.A., Gaffarov S.A., Khozhimetov A.A. Maktab yoshdagi bolalarda hepatobiliary tizimning tish-zhaғ nuқsonlari pathogenesis axamiyati. // Journal of Doctor ahborotnomasi. Samarkand. 2019 - 
No. 2. - 35-39 bet.

28. Olimov S.Sh. Evaluation of the effectiveness of preventive measures in the orthodontic treatment of children with dentoalveolar deformities. // uv-usubiy қy̆llanma. Y̌zR SSV tomonidan 13.11 .08 tasdiқlangan. Tashkent. 2019. - $21 \mathrm{p}$.

29. Stepanov, G.V. Change in blood flow velocity in the area of retinated canals of the upper jaw. Stepanov // Orthodontics. - 2002. -№ 1.-S. 39-41.

30. Stepanov, G.V. Complex diagnostics and treatment of bite anomalies in case of dental alveolar shortening: author. dis. ... Dr. honey. Sciences: 14.01.14 / Stepanov Grigoriy Viktorovich. - Samara, 2011 .-- 43p.

31 Becker, A. Success rate and durations of orthodontic treatment for adult patients with palatally impacted maxillary canines / A. Becker, S. Chaushu // Am. J. Orthod Dentofacial Orthop. - 2003. - Vol. 124, No. 5. - P. 509-514. 